\title{
Primary site surgery for elderly patients with distant metastatic pancreatic neuroendocrine tumor: to do or not to do?
}

This article was published in the following Dove Press journal:

Clinical Interventions in Aging

\author{
Jing Zhang' \\ Chao-Sheng Peng ${ }^{2, *}$ \\ Yu-Hong $\operatorname{Tian}^{3, *}$ \\ 'Bachelor of Nursing, Special Medical \\ Department, The Sixth Medical Center of \\ People's Liberation Army General \\ Hospital (The Former Naval General \\ Hospital of PLA), Beijing, People's \\ Republic of China; ${ }^{2}$ Special Medical \\ Department, The Sixth Medical Center of \\ People's Liberation Army General \\ Hospital (The Former Naval General \\ Hospital of PLA), Beijing, People's \\ Republic of China; ${ }^{3}$ Bachelor of Nursing. \\ Special Medical Department, The Sixth \\ Medical Center of People's Liberation \\ Army General Hospital (The Former \\ Naval General Hospital of PLA), Beijing, \\ People's Republic of China
}

*These authors contributed equally to this work
Correspondence: Chao-Sheng Peng; Yu-Hong Tian

Special Medical Department, The Sixth Medical Center of People's Liberation Army General Hospital (The Former Naval General Hospital of PLA), No. 6 Fucheng Road, Haidian District, Beijing, People's Republic of China

$\mathrm{Tel}+860 \mathrm{I06} 695 \mathrm{I} 40 \mathrm{I}$

$+8601066951405$

Fax +86 $0106695 \quad 1403$

Email pcslbbd@sina.com;

tyhtxyl@sina.com
Objective: To investigate the effect of primary site surgery (PSS) on elderly patients $(\geq 65$ years) with pancreatic neuroendocrine tumor (pNET) distant metastasis.

Patients and methods: We reviewed Surveillance Epidemiology and the End Results database for elderly patients with distant pNET from 1973 to 2015. The variables and survival outcomes of patients with PSS were compared with that of patients with no PSS. After propensity score matching, the survival outcome was compared again between the two groups. Multivariable Cox proportional hazard model was used to identify variables associated with cancer-specific and overall survival. Four sub-groups were divided according to the age and differentiation: 1) age 65-74 years + well or moderately differentiated; 2) age $\geq 75$ years + well or moderately differentiated; 3 ) age 65-74 years + poorly differentiated or undifferentiated; and 4) age $\geq 75$ years + poorly differentiated or undifferentiated. Cancer-specific survival was compared between the patients with and without PSS in the above each group.

Results: A total of 210 elderly patients with distant pNET were finally confirmed. Of which, 148 patients did not undergo PSS, while 62 patients underwent PSS. Being female $(p=0.049)$, locating on body/tail of pancreas $(p=0.006)$, and well or moderately differentiated $(p=0.032)$ were more likely received PSS. The patients underwent PSS had better survival outcomes both before and after propensity score matching. Multivariable Cox proportional hazard analysis proves PSS and higher histological grade to be protective and risk factors. PSS may improve cancer specific survival in patients of group 1), and no improvement was observed in patients of the other three sub-groups.

Conclusion: Not all elderly patients with pNET distant metastasis could benefit from PSS. Patients aged 65-74 years with well or moderately differentiated may benefit from primary lesion surgery, but should be evaluated carefully. Prospective randomized controlled trials are worth performing.

Keywords: primary site surgery, pancreatic neuroendocrine tumor, distant metastasis, elderly patients

\section{Introduction}

As a rare neoplasm, pancreatic neuroendocrine tumor ( $\mathrm{pNET}$ ) originates from pancreatic neuroendocrine cells and may occur in various organs, including lung, gastrointestinal tract, pancreas, etc. ${ }^{1,2}$ pNETs represent approximately $7 \%$ of all NETs and account for $1-$ $2 \%$ of all pancreatic malignancies. ${ }^{1-3}$ Over the past several decades, the incidence of pNET has been increasing in the United States. ${ }^{4}$ pNETs have great variance in biological behavior. Most of the pNETs have low malignant behavior and slow growth rate, but some of them possess high ability of invasiveness. ${ }^{5}$ Up to $60-80 \%$ of patients develop 
distant metastasis during the course of this disease. ${ }^{6,7}$ Based on the data from Surveillance Epidemiology and End Results (SEER) database from 1973 to 2015 in the current study, $50.0 \%$ of the pNET patients (4212/8422) were distant metastasis at the first diagnosis. Previous studies have revealed that the presence of distant metastatic is one of the strongest predictors for patients' survival. The 5-year survival rate (13$54 \%$ ) was significantly worse than patients without liver metastasis $(75-99 \%))^{8,9}$

Distant metastatic pNET requires systematic treatment, which includes somatostatin analogs (SSA), molecular targeted therapy, chemotherapy, peptide receptor radionuclide therapy (PRRT), etc. ${ }^{10}$ Previous studies have indicated that the primary site surgery (PSS) can improve the survival of patients with distant metastatic pNET. ${ }^{11,12}$ With the aggravation of social aging, the number of elderly cancer patients is increasing gradually. Elderly patients account for a considerable proportion of cancerous cases. ${ }^{13,14}$ In the current study, elderly patients ( $\geq 65$ years) account for $40.7 \%$ (3431/ 8422) of all pNET patients between 1973 and 2015 in SEER database. In the distant metastatic cases, elderly patients ( $\geq 65$ years) account for $41.4 \%$ (1743/4212) in SEER database. The elderly patients have special physiological and pathological characteristics, such as more complications, poor tolerance to surgery, and high mortality after surgery. ${ }^{15}$ Is it justifiable to perform the PSS in elderly patients with distant metastasis of pNET, which is seldom elucidated in the existing literature. We performed a study solely focusing on the elderly patients ( $\geq 65$ years) with pNET distant metastasis based on the SEER database, to investigate the effect of PSS on elderly patients with pNET distant metastasis.

\section{Patients and methods}

\section{Patient demographic and clinical data}

We queried SEER database for patients with pNET from 1973 to 2015, using SEER*Stat software version 8.3.5. The data accessed from SEER are freely available. PNET was defined as including the following International Classification of Diseases for Oncology third edition (ICD-O3) codes: 8150/3, 8151/3, 8152/3, 8153/3, 8155/3, $8156 / 3,8240 / 2,8240 / 3,8241 / 3,8242 / 3,8243 / 3,8246 / 2$, $8246 / 3,8249 / 3$. All pancreatic anatomical sites were included (C25.0-C25.9) in our study. Patients with stage IV pNET diagnosed between 1973 and 2015 were selected. Only the cases with diagnoses based on histological studies were included, while cases whose diagnoses relied only on autopsies or were detailed only on death certificates were excluded. A total of 8422 patients suffered pNET, and 4212 patients have distant metastasis.

Patients exclusion criteria include (see Figure 1):

Combined with other primary tumor;

Incomplete data;

Survival month $\leq 1$ month;

Patients with age $<65$ years.

\section{Patient data collection and outcome measurement}

We collected patients demographic and tumor characteristics concerning age, gender, race,primary site of tumor, histological grade, year of diagnosis, tumor size, PSS, marital status, survival months, SEER cause-specific survival, and overall survival. Cancer-specific survival was defined as the duration from diagnosis to death attributable to the pNET. Overall survival was defined as the duration from diagnosis to death from any cause.

The variables of patients with PSS were compared with that of patients with no PSS. The overall survival and cancer-specific survival were also compared with logrank test between the two groups before and after the propensity score matching of the variables. The primary survival outcome measure was cancer-specific survival. Multivariable Cox proportional hazard model was used to identify variables associated with cancer-specific survival and overall survival before and after propensity score matching.

In order to further study the effects of PSS on different age and differentiation group, patients were further divided into four sub-groups: 1) age 65-74 years + well or moderately differentiated; 2 ) age $\geq 75$ years + well or moderately differentiated; 3 ) age $65-74$ years + poorly differentiated or undifferentiated; and 4) age $\geq 75$ years + poorly differentiated or undifferentiated. Cancer-specific survival was compared between the patients with PSS and the patients without PSS using Kaplan-Meier survival analysis with log-rank test and multivariable Cox proportional analysis in the above each group. The cutoff value of age was identified by X-tile. ${ }^{16}$

The data accessed from SEER are freely available. This study does not contain any studies with human participants or animals performed by any of the authors. In addition, according to the guidelines of the government of the United States, data released through the SEER database donot require informed patient consent. 


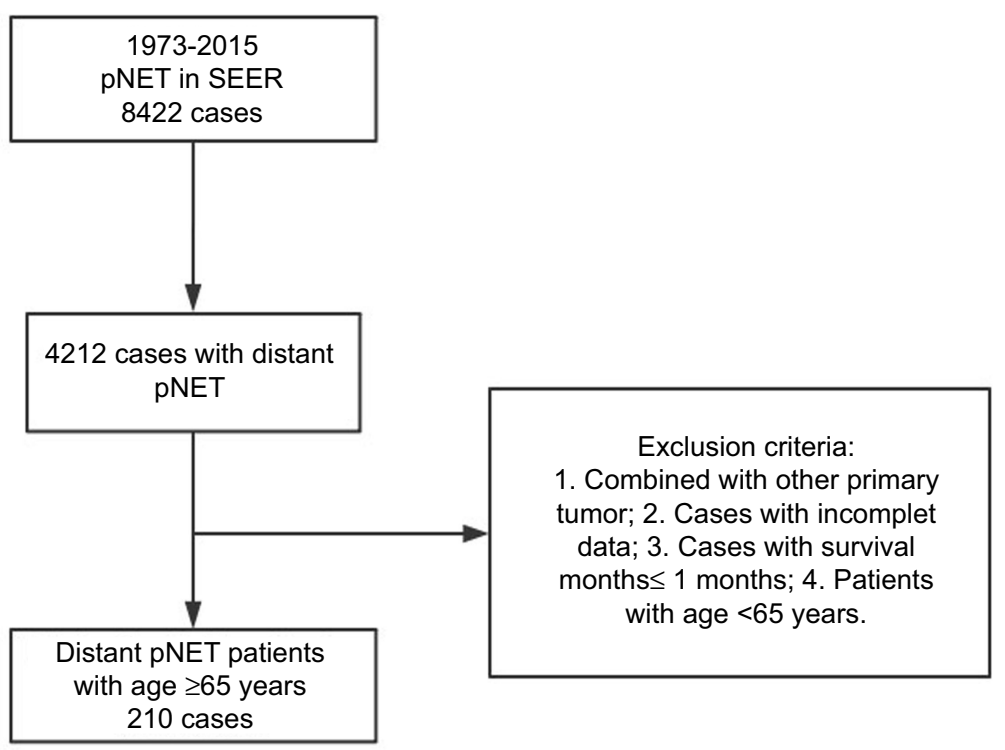

Figure I Patient screening process.

Abbreviations: pNET, pancreatic neuroendocrine tumor; SEER, Surveillance Epidemiology and End Results.

\section{Statistical analyses}

A two-sided $p<0.05$ was considered statistically significant and the analyses were performed by IBM SPSS Statistics 22.0 (SPSS Inc., Chicago, IL, USA) and GraphPad Prism version 7.0 (GraphPad Software, USA). Pearson and Fisher chi-square tests were performed before and after PSM to compare the characteristics of patients with and without PSS. To balance the potential baseline confounding variables between the two groups, a propensity score matching method was performed by the "MatchIt" $\mathrm{R}$ package and the "nearest neighbor matching" method (ratio=1:1). Kaplan-Meier survival analysis with a logrank test was performed to plot survival curves and to calculate the cancer-specific survival and overall survival rate. Multivariable Cox proportional hazard model was used to identify variables associated with cancer-specific survival and overall survival before and after propensity score matching. HRs were presented with 95\% CI.

\section{Result}

\section{Patient clinico-pathological features}

A total of 210 patients were finally confirmed after screened out the unqualified patients. Of which, 148 elderly pNET patients with distant metastasis did not undergo PSS, while 62 patients underwent PSS. Being female $(p=0.049)$, locating on body/tail of pancreas $(p=0.006)$, and histological grade of well or moderately differentiated $(p=0.032)$ were more likely received PSS
(Table 1). After propensity score matching, all variables were comparable between the two groups (Table 1).

\section{Logistic regression analysis of characteristics associated with elderly patients ( $\geq 65$ years) who underwent PSS}

The univariate regression analysis for PSS was performed to patients with age $\geq 65$ years (Table 2 ). The variables with univariate logistic analysis $p<0.1$ were further analyzed using multivariate logistic regression. Being female ( $p=0.012$, OR: 2.329, 95\% CI: 1.204-4.503), and tumor locating at body/tail of pancreas ( $p=0.001$, OR: 3.780, 95\% CI: 1.749-8.170) were more likely received PSS, while tumor with histological grade of poorly differentiated/undifferentiated $(p=0.040, \mathrm{OR}$ : 0.455 , 95\% CI: $0.215-0.964)$ had decreased possibility of receipt of PSS (Table 2).

\section{Kaplan-Meier analysis with log-rank test, and multivariable Cox proportional hazard analysis before propensity score matching and after propensity score matching}

The Kaplan-Meier analysis with log-rank test proved that PSS in distant metastatic pNET patients with age $\geq 65$ years had better cancer-specific survival and overall survival both before and after propensity score matching (Figure 2). Multivariable Cox proportional hazard analysis was performed for all 210 patients before propensity score 
Table I Characteristics of patients older than 65 years included in the study

\begin{tabular}{|c|c|c|c|c|c|c|}
\hline \multirow[t]{2}{*}{ Variables } & \multicolumn{3}{|l|}{ Before PSM } & \multicolumn{3}{|l|}{ After PSM } \\
\hline & NPSS, N= I 48 & PSS, $N=62$ & $p$ & NPSS, $N=62$ & PSS, $\mathbf{N}=62$ & $p$ \\
\hline $\begin{array}{l}\text { Age } \\
\qquad 65-75 \text { years } \\
\geq 75 \text { years }\end{array}$ & $\begin{array}{l}95(64.2 \%) \\
53(35.8 \%)\end{array}$ & $\begin{array}{l}45(72.6 \%) \\
17(27.4 \%)\end{array}$ & 0.265 & $\begin{array}{l}35(56.5 \%) \\
27(43.5 \%)\end{array}$ & $\begin{array}{l}45(72.6 \%) \\
17(27.4 \%)\end{array}$ & 0.091 \\
\hline $\begin{array}{l}\text { Gender } \\
\text { Male } \\
\text { Female }\end{array}$ & $\begin{array}{l}89(60.1 \%) \\
59(39.9 \%)\end{array}$ & $\begin{array}{l}28(45.2 \%) \\
34(54.8 \%)\end{array}$ & 0.049 & $\begin{array}{l}35(56.5 \%) \\
27(43.5 \%)\end{array}$ & $\begin{array}{l}28(45.2 \%) \\
34(54.8 \%)\end{array}$ & 0.281 \\
\hline $\begin{array}{l}\text { Race } \\
\text { White } \\
\text { Black } \\
\text { Other }\end{array}$ & $\begin{array}{l}123(83.1 \%) \\
16(10.8 \%) \\
9(6.1 \%)\end{array}$ & $\begin{array}{l}57(91.9 \%) \\
3(4.8 \%) \\
2(3.2 \%)\end{array}$ & 0.247 & $\begin{array}{l}50(80.6 \%) \\
9(14.5 \%) \\
3(4.8 \%)\end{array}$ & $\begin{array}{l}57(91.9 \%) \\
3(4.8 \%) \\
2(3.2 \%)\end{array}$ & 0.161 \\
\hline $\begin{array}{l}\text { Marital status } \\
\text { Married } \\
\text { Unmarried }\end{array}$ & $\begin{array}{l}96(64.9 \%) \\
52(35.1 \%)\end{array}$ & $\begin{array}{l}38 \text { (6I.3\%) } \\
24(38.7 \%)\end{array}$ & 0.639 & $\begin{array}{l}36(58.1 \%) \\
26(41.9 \%)\end{array}$ & $\begin{array}{l}38(61.3 \%) \\
24(38.7 \%)\end{array}$ & 0.855 \\
\hline $\begin{array}{l}\text { Year of diagnosis } \\
\begin{array}{l}1973-2009 \\
2010-2015\end{array}\end{array}$ & $\begin{array}{l}53(35.8 \%) \\
95(64.2 \%)\end{array}$ & $\begin{array}{l}21(33.9 \%) \\
41(66.1 \%)\end{array}$ & 0.875 & $\begin{array}{l}18(29.0 \%) \\
44(71.0 \%)\end{array}$ & $\begin{array}{l}21(33.9 \%) \\
41(66.1 \%)\end{array}$ & 0.699 \\
\hline $\begin{array}{l}\text { Tumor site } \\
\text { Head } \\
\text { Body/tail } \\
\text { Overlap } \\
\text { Other }\end{array}$ & $\begin{array}{l}58(39.2 \%) \\
62(41.9 \%) \\
21(14.2 \%) \\
7(4.7 \%)\end{array}$ & $\begin{array}{l}12(19.4 \%) \\
42(67.7 \%) \\
7(11.3 \%) \\
1(1.6 \%)\end{array}$ & 0.006 & $\begin{array}{l}16(25.8 \%) \\
35(56.5 \%) \\
8(12.9 \%) \\
3(4.8 \%)\end{array}$ & $\begin{array}{l}12(19.4 \%) \\
42(67.7 \%) \\
7(11.3 \%) \\
1(1.6 \%)\end{array}$ & 0.517 \\
\hline $\begin{array}{l}\text { Tumor size } \\
\qquad 4 \mathrm{~cm} \\
>4 \mathrm{~cm} \\
\text { Unknown }\end{array}$ & $\begin{array}{l}48(32.4 \%) \\
67(45.3 \%) \\
33(22.3 \%)\end{array}$ & $\begin{array}{l}21(33.9 \%) \\
4 I(66.1 \%) \\
0(0 \%)\end{array}$ & 0.000 & $\begin{array}{l}29(46.8 \%) \\
31(50.0 \%) \\
2(3.2 \%)\end{array}$ & $\begin{array}{l}21(33.9 \%) \\
4 I(66.1 \%) \\
0(0 \%)\end{array}$ & 0.097 \\
\hline $\begin{array}{l}\text { Histological grade } \\
\text { Well/moderately } \\
\text { Poorly/undifferentiated }\end{array}$ & $\begin{array}{l}97(65.5 \%) \\
5 I(34.5 \%)\end{array}$ & $\begin{array}{l}50(80.6 \%) \\
12(19.4 \%)\end{array}$ & 0.032 & $\begin{array}{l}50(80.6 \%) \\
12(19.4 \%)\end{array}$ & $\begin{array}{l}50(80.6 \%) \\
12(19.4 \%)\end{array}$ & 1.000 \\
\hline
\end{tabular}

Notes: Race: other included American Indian/AK, Native Asian/Pacific Islander. Marital status: unmarried included divorced/separated/single (never married)/unmarried or domestic partner/widowed. Tumor site: "Other" included Islets of langerhans+other specific parts of pancreas+NOS of pancreas.

Abbreviations: PSM, propensity score matching; NPSS, no primary site surgery; PSS, primary site surgery; $\mathrm{cm}$, centimeter.

matching. Histological grade of poorly differentiated/ undifferentiated was risk factor for both overall survival (HR: $3.062,95 \%$ CI: $2.118-4.425, p<0.001$ ) and cancerspecific survival (HR 3.641, 95\% CI 2.351-5.640, $p<0.001$ ), and PSS was proved to be protective factor for overall survival (HR: 0.392 , 95\% CI: $0.252-0.612$, $p<0.001$ ) and cancer-specific survival (HR: 0.362, 95\% CI: $0.206-0.637, p<0.001$ ) (see Table 3). After propensity score matching, multivariable Cox proportional hazard analysis was performed for 124 patients. Histological grade of poorly differentiated/undifferentiated was also proved to be risk factor for both overall survival (HR: 4.020, 95\% CI: $2.203-7.336, p<0.001)$ and cancer-specific survival (HR: 6.574, 95\% CI: 3.261-13.251, $p<0.001$ ), and PSS was also proved to be protective factor for overall survival (HR: $0.212,95 \%$ CI: $0.125-0.360, p<0.001$ ) and cancer-specific survival (HR: $0.210,95 \%$ CI: $0.110-0.403$, $p<0.001$ ). (See Table 4)

\section{Kaplan-Meier analysis with log-rank test} and multivariable Cox proportional analysis for sub-groups of elderly patients with PNET distant metastasis

Cases with PSS had a cancer-specific survival advantage comparing with cases with no PSS in the sub-group of 1) 
Table 2 Logistic regression analysis of characteristics for PSS in elderly patients ( $\geq 65$ years)

\begin{tabular}{|c|c|c|c|c|c|c|}
\hline \multirow[t]{2}{*}{ Variables } & \multicolumn{3}{|c|}{ Univariate analysis for PSS } & \multicolumn{3}{|c|}{ Multivariate analysis for PSS } \\
\hline & OR & $95 \% \mathrm{Cl}$ & $p$ & OR & $95 \% \mathrm{Cl}$ & $p$ \\
\hline \multicolumn{7}{|l|}{ Age } \\
\hline $65-75$ years & I (Referent) & & & & & \\
\hline$>75$ years & 0.677 & $0.353-1.299$ & 0.241 & & & \\
\hline \multicolumn{7}{|l|}{ Gender } \\
\hline Male & I (Referent) & & & I (Referent) & & \\
\hline Female & 1.832 & $1.007-3.333$ & 0.048 & 2.329 & $1.204-4.503$ & 0.012 \\
\hline \multicolumn{7}{|l|}{ Race } \\
\hline White & I (Referent) & & & & & \\
\hline Black & 0.405 & $0.113-1.444$ & 0.163 & & & \\
\hline Other & 0.480 & $0.100-2.291$ & 0.357 & & & \\
\hline \multicolumn{7}{|l|}{ Marital status } \\
\hline Married & I (Referent) & & & & & \\
\hline Unmarried & 1.166 & $0.632-2.151$ & 0.623 & & & \\
\hline \multicolumn{7}{|l|}{ Year of diagnosis } \\
\hline $1973-2009$ & I (Referent) & & & & & \\
\hline $2010-2015$ & 1.089 & $0.584-2.033$ & 0.788 & & & \\
\hline \multicolumn{7}{|l|}{ Tumor site } \\
\hline Head & I (Referent) & & & I (Referent) & & \\
\hline Body/tail & 3.274 & $1.570-6.826$ & 0.002 & 3.780 & $1.749-8.170$ & 0.001 \\
\hline Overlap & 1.611 & $0.560-4.638$ & 0.377 & $\mathrm{I} .24 \mathrm{I}$ & $0.4|8-3.68|$ & 0.697 \\
\hline Other & 0.690 & $0.078-6.142$ & 0.740 & 0.711 & $0.077-6.535$ & 0.763 \\
\hline \multicolumn{7}{|l|}{ Histological grade } \\
\hline Well/moderately & I (Referent) & & & I (Referent) & & \\
\hline Poorly/undifferentiated & 0.456 & $0.223-0.934$ & 0.032 & 0.455 & $0.215-0.964$ & 0.040 \\
\hline \multicolumn{7}{|l|}{ Tumor size } \\
\hline$\leq 4 \mathrm{~cm}$ & I (Referent) & & & & & \\
\hline$>4 \mathrm{~cm}$ & 1.399 & $0.735-2.662$ & 0.485 & & & \\
\hline Unknown & & & NA & & & \\
\hline
\end{tabular}

Note: Variables with univariate analysis $p<0.1$ underwent further multivariate analysis. Abbreviation: PSS, primary site surgery.

age 65-74 years + well or moderately differentiated $(p<0.001) \quad$ (Figure 3A). However, no differences were observed regarding cancer-specific survival in the subgroups of 2) age $\geq 75$ years + well or moderately differentiated $(p=0.229)$ (Figure $3 \mathrm{~B}), 3)$ age $65-74$ years + poorly differentiated or undifferentiated $(p=0.237)$ (Figure $3 \mathrm{C}$ ), and $4)$ age $\geq 75$ years + poorly differentiated or undifferentiated ( $p=0.655$ ) (Figure 3D). Multivariable Cox proportional analysis was performed for the four sub-groups, and PSS was an independent protective factor only in cases with age of 65-74 years and well or moderately differentiated tumors
(HR 0.142, 95\% CI $0.053-0.379, p<0.001$ ) (supplemental materials).

\section{Discussion}

Patients with distant metastasis of pNET are often treated with comprehensive therapy, including SSA, molecular targeted therapy, chemotherapy, PRRT, etc. ${ }^{10}$ Many studies advocate PSS in the setting of metastatic pNET for reasons that PSS can improve the control of endocrine-related symptoms, relieve the symptoms of compression and may prolong the survival time of patients. ${ }^{11,12,17,18}$ However, with the increase of the elderly 

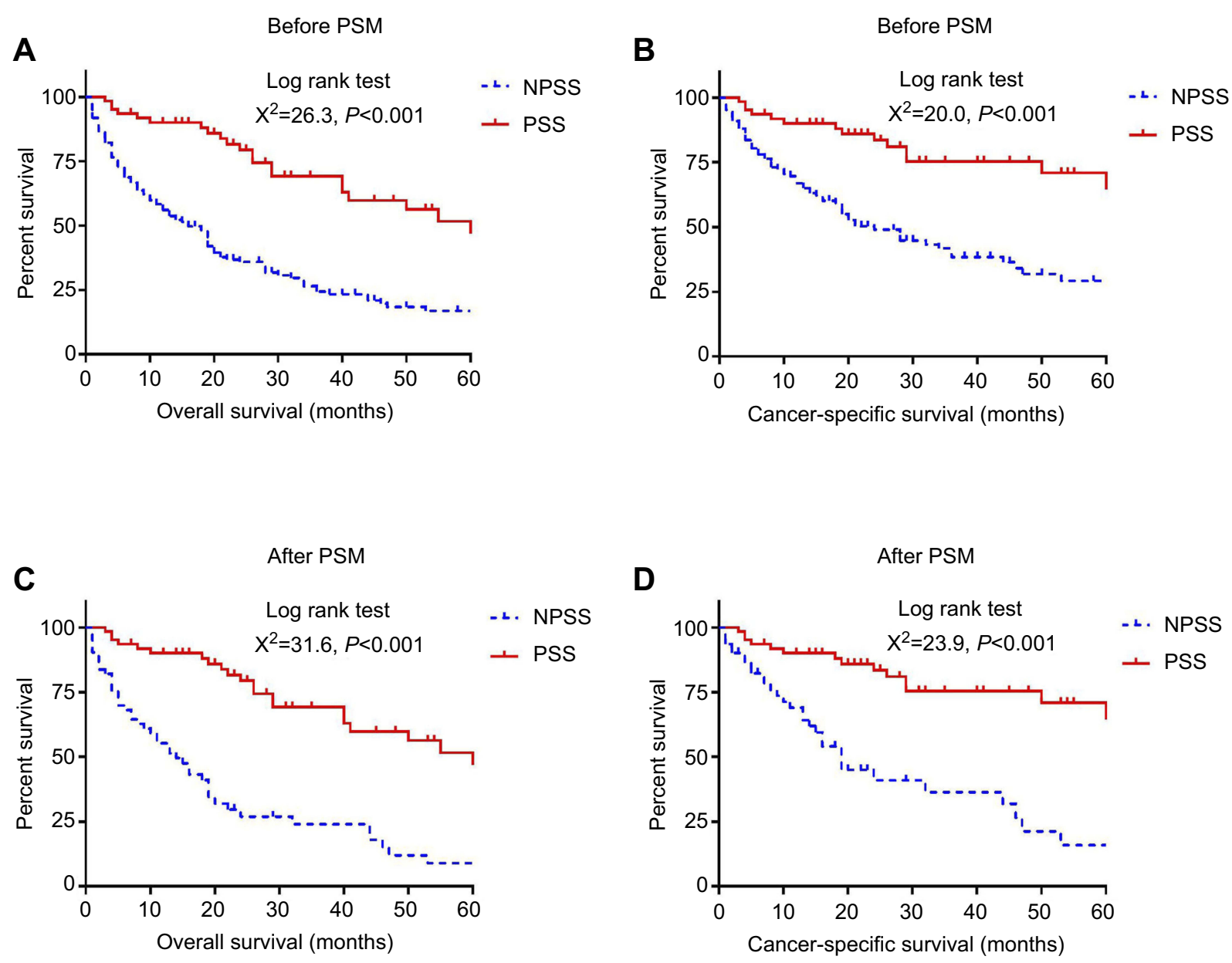

Figure 2 Overall survival and cancer-specific survival in elderly patients ( $\geq 65$ years) with metastatic pNET who underwent primary site surgery (PSS) and no primary site surgery (NPSS), before and after propensity score matching (PSM).

Notes: (A) Kaplan-meier analysis for overall survival in elderly patients ( $\geq 65$ years) who underwent PSS and NPSS before PSM; (B) Kaplan-meier analysis for cancer-specific survival in elderly patients ( $\geq 65$ years) who underwent PSS and NPSS before PSM; (C) Kaplan-meier analysis for overall survival in elderly patients ( $\geq 65$ years) who underwent PSS and NPSS after PSM; (D) Kaplan-meier analysis for cancer-specific survival in elderly patients ( $\geq 65$ years) who underwent PSS and NPSS after PSM.

population, there is still few clinical evidence on the suitability of the elderly with metastatic pNET to accept PSS. The elderly patients usually have a higher incidence of comorbidities, such as chronic obstructive pulmonary disease, hypertension, coronary artery disease, and diabetes mellitus, which may increase the death rate and reduce the possibility of receipt of endocrine therapy, chemotherapy, targeted therapy, and surgery. ${ }^{15}$ Given the absence of clinical evidence, the study focusing on the suitability of PSS for elderly patients with metastatic pNET is necessary.

In the current study, female patients are more likely to receive PSS, which may be associated with fewer comorbidities in elderly women. There are more tumors receiving PSS in the body/tail of the pancreas than in the head of the pancreas. This may be related to the fact that the complexity of surgery of pancreatic body/tail is less than that of the surgery of pancreatic head. After all, the tumors locating on the head of pancreas need pancreaticoduodenectomy, whereas the former only needs the resection of pancreatic body and tail. In addition, it is not surprising that poorly differentiated and undifferentiated tumors are less likely to undergo surgery than well-differentiated tumors, because the patients with poorly differentiated and undifferentiated tumors have worse prognosis and are more likely receiving conservative treatment options. However, the rate of PSS in the greater elderly patients ( $\geq 75$ years) is not different from that in the elderly patients (65-74 years) (see Table 2).

Both before and after propensity score matching, tumor histological grade of poorly differentiation and undifferentiation is an independent risk factor for overall survival and cancer-specific survival, whereas PSS is an independent protective factor (see Tables 3, 4 and Figure 2). Then, in order to further explore whether elderly patients with metastatic pNET are suitable for PSS, a further sub-grouping of age and 
Table 3 Multivariate regression analysis of characteristics for survival in elderly patients ( $\geq 65$ years) before PSM

\begin{tabular}{|c|c|c|c|c|c|c|}
\hline \multirow[t]{2}{*}{ Variables } & \multicolumn{3}{|c|}{ Multivariate analysis for OS } & \multicolumn{3}{|c|}{ Multivariate analysis for CSS } \\
\hline & HR & $95 \% \mathrm{Cl}$ & $p$ & HR & $95 \% \mathrm{Cl}$ & $p$ \\
\hline \multicolumn{7}{|l|}{ Age } \\
\hline $65-75$ years & I (Referent) & & & I (Referent) & & \\
\hline$>75$ years & 1.373 & $0.954-1.977$ & 0.088 & 1.231 & $0.775-1.955$ & 0.378 \\
\hline \multicolumn{7}{|l|}{ Gender } \\
\hline Male & I (Referent) & & & I (Referent) & & \\
\hline Female & 1.028 & $0.678-1.557$ & 0.898 & 0.939 & $0.57 \mid-1.544$ & 0.803 \\
\hline \multicolumn{7}{|l|}{ Race } \\
\hline White & I (Referent) & & & I (Referent) & & \\
\hline Black & 1.367 & $0.726-2.572$ & 0.333 & 1.333 & $0.621-2.859$ & 0.460 \\
\hline Other & 1.598 & $0.782-3.269$ & 0.199 & 1.767 & $0.777-4.018$ & 0.175 \\
\hline \multicolumn{7}{|l|}{ Marital status } \\
\hline Married & I (Referent) & & & I (Referent) & & \\
\hline Unmarried & 1.228 & $0.852-1.770$ & 0.271 & 1.417 & $0.906-2.217$ & 0.127 \\
\hline \multicolumn{7}{|l|}{ Year of diagnosis } \\
\hline 1973-2009 & I (Referent) & & & I (Referent) & & \\
\hline $2010-2015$ & 0.931 & $0.634-1.365$ & 0.714 & 1.027 & $0.638-1.65 \mid$ & 0.913 \\
\hline \multicolumn{7}{|l|}{ Tumor site } \\
\hline Head & I (Referent) & & & I (Referent) & & \\
\hline Body/tail & 1.104 & $0.734-1.661$ & 0.635 & 0.872 & $0.538-1.415$ & 0.580 \\
\hline Overlap & 1.226 & $0.692-2.171$ & 0.485 & 0.859 & $0.422-1.749$ & 0.676 \\
\hline Other & 1.709 & $0.784-3.729$ & 0.178 & 1.758 & $0.773-3.997$ & 0.178 \\
\hline \multicolumn{7}{|l|}{ Histological grade } \\
\hline Well/moderately & I (Referent) & & & I (Referent) & & \\
\hline Poorly/undifferentiated & 3.062 & $2.118-4.425$ & 0.000 & 3.641 & $2.35 I-5.640$ & 0.000 \\
\hline \multicolumn{7}{|l|}{ Tumor size } \\
\hline$\leq 4 \mathrm{~cm}$ & I (Referent) & & & I (Referent) & & \\
\hline$>4 \mathrm{~cm}$ & 0.862 & $0.568-1.308$ & 0.485 & 0.790 & $0.476-1.310$ & 0.361 \\
\hline Unknown & 0.798 & $0.463-1.375$ & 0.416 & 0.812 & $0.423-1.558$ & 0.531 \\
\hline \multicolumn{7}{|l|}{ Primary site surgery } \\
\hline No & I (Referent) & & & I (Referent) & & \\
\hline Yes & 0.392 & $0.252-0.612$ & 0.000 & 0.362 & $0.206-0.637$ & 0.000 \\
\hline
\end{tabular}

Note: Variables with univariate analysis $p<0.1$ underwent further multivariate analysis.

Abbreviations: OS, overall survival; CSS, cancer-specific survival; PSM, propensity score matching.

differentiation was performed. The reason for choosing 75 years for further grouping is that WHO stipulates that the older elderly are over 75 years old. ${ }^{15}$ In addition, X-tiles are also used to determine the cutoff value of age. From the results of the present study, patients with age $\geq 65$ years with poorly differentiated and undifferentiated pNETs are not suitable to receive PSS. For well and moderately differentiated metastatic pNETs, only those aged 65-74 are suitable for PSS, while those aged $\geq 75$ are not suitable for PSS, because there is no difference in cancer-specific survival between PSS and no PSS patients. The physical condition of the patients with age $\geq 75$ years is worse than that of other patients, and their physical state, surgical tolerance, and antineoplastic immunity are decreased. These may be the explanation of the fact that even accepting PSS does not improve cancer-specific survival for cases with age $\geq 75$ years and histological grade of well and moderately differentiation.

It should be pointed out that selection bias may exist in the present study. Firstly, patients who have not undergone surgery may be too ill to perform surgery. Secondly, it is impossible to 
Table 4 Multivariate regression analysis of characteristics for survival in elderly patients (Table 4: Multfter PSM)

\begin{tabular}{|c|c|c|c|c|c|c|}
\hline \multirow[t]{2}{*}{ Variables } & \multicolumn{3}{|c|}{ Multivariate analysis for OS } & \multicolumn{3}{|c|}{ Multivariate analysis for CSS } \\
\hline & HR & $95 \% \mathrm{Cl}$ & $p$ & HR & $95 \% \mathrm{Cl}$ & $p$ \\
\hline \multicolumn{7}{|l|}{ Age } \\
\hline $65-75$ years & I (Referent) & & & I (Referent) & & \\
\hline$>75$ years & 1.442 & $0.852-2.442$ & 0.173 & 1.224 & $0.648-2.311$ & 0.533 \\
\hline \multicolumn{7}{|l|}{ Gender } \\
\hline Male & I (Referent) & & & I (Referent) & & \\
\hline Female & 1.591 & $0.880-2.877$ & 0.125 & 1.378 & $0.688-2.758$ & 0.366 \\
\hline \multicolumn{7}{|l|}{ Race } \\
\hline White & I (Referent) & & & I (Referent) & & \\
\hline Black & $1.37 \mid$ & $0.602-3.124$ & 0.452 & 1.031 & $0.377-2.817$ & 0.953 \\
\hline Other & 2.705 & $0.959-7.628$ & 0.060 & 3.864 & $1.340-11.143$ & 0.012 \\
\hline \multicolumn{7}{|l|}{ Marital status } \\
\hline Married & I (Referent) & & & I (Referent) & & \\
\hline Unmarried & 1.309 & $0.750-2.288$ & 0.344 & 1.370 & $0.694-2.703$ & 0.364 \\
\hline \multicolumn{7}{|l|}{ Year of diagnosis } \\
\hline $1973-2009$ & I (Referent) & & & I (Referent) & & \\
\hline $2010-2015$ & 0.909 & $0.482-1.714$ & 0.769 & 0.931 & $0.413-2.100$ & 0.863 \\
\hline \multicolumn{7}{|l|}{ Tumor site } \\
\hline Head & I (Referent) & & & I (Referent) & & \\
\hline Body/tail & 0.649 & $0.347-1.214$ & 0.176 & 0.664 & $0.303-1.456$ & 0.307 \\
\hline Overlap & 0.694 & $0.288-1.670$ & $0.4 I 4$ & 0.530 & $0.164-1.706$ & 0.287 \\
\hline Other & 0.423 & $0.129-1.384$ & 0.155 & 0.602 & $0.167-2.171$ & 0.438 \\
\hline \multicolumn{7}{|l|}{ Histological grade } \\
\hline Well/moderately & I (Referent) & & & I (Referent) & & \\
\hline Poorly/undifferentiated & 4.020 & $2.203-7.336$ & 0.000 & 6.574 & $3.26 I-13.25 \mid$ & 0.000 \\
\hline \multicolumn{7}{|l|}{ Tumor size } \\
\hline$\leq 4 \mathrm{~cm}$ & I (Referent) & & & I (Referent) & & \\
\hline$>4 \mathrm{~cm}$ & 1.058 & $0.618-1.813$ & 0.836 & 1.087 & $0.548-2.157$ & 0.811 \\
\hline Unknown & $0.70 \mathrm{I}$ & $0.114-4.324$ & 0.702 & 1.070 & $0.162-7.080$ & 0.944 \\
\hline \multicolumn{7}{|l|}{ Primary site surgery } \\
\hline No & I (Referent) & & & I (Referent) & & \\
\hline Yes & 0.212 & $0.125-0.360$ & 0.000 & 0.210 & $0.110-0.403$ & 0.000 \\
\hline
\end{tabular}

Note: Variables with univariate analysis $p<0.1$ underwent further multivariate analysis.

Abbreviations: OS, overall survival; CSS, cancer-specific survival; PSM, propensity score matching.

determine whether the two groups are completely balanced in other treatments (such as SSA, chemotherapy, molecular targeted therapy or PRRT, etc.) due to the lack of other treatment information. In addition, there are other limitations that need to be addressed. First, there is a lack of information related to surgery. We can not obtain the duration of surgery, blood loss, complications, and so on. Secondly, the number of patients administrated in the study was relatively small, especially after further divided sub-groups. Thirdly, we can not know the exact reason for the surgery due to the lack of relevant information.
Judging from the common sense, patients undergoing surgery should be in better physical conditions and are more likely to receive a variety of treatment options. The no prolonged survival time after surgery may be more indicative of the ineffectiveness of PSS for these patients. Patients in the three sub-groups (age $\geq 75$ years + well or moderately differentiated, age 65-74 years ${ }^{+}$poorly differentiated or undifferentiated, and age $\geq 75$ years + poorly differentiated or undifferentiated) did not have a better prognosis after surgery, which suggests that patients of these three sub-groups are less likely to benefit from 
Age:65-74 years

A well differentiated or moderately differentiated

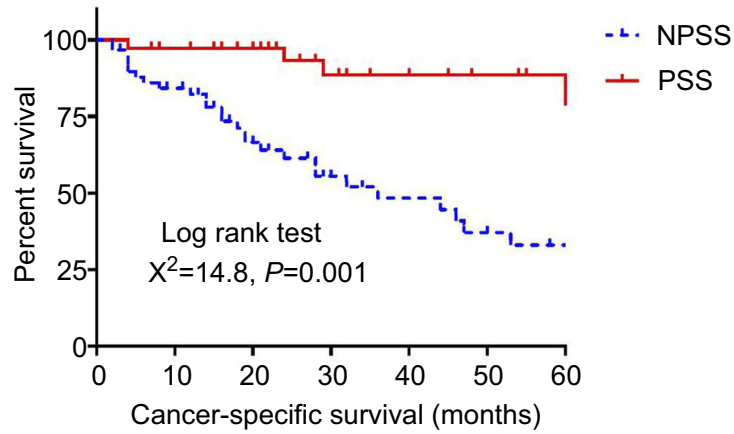

C

Age:65-74 years poorly differentiated or undifferentiated

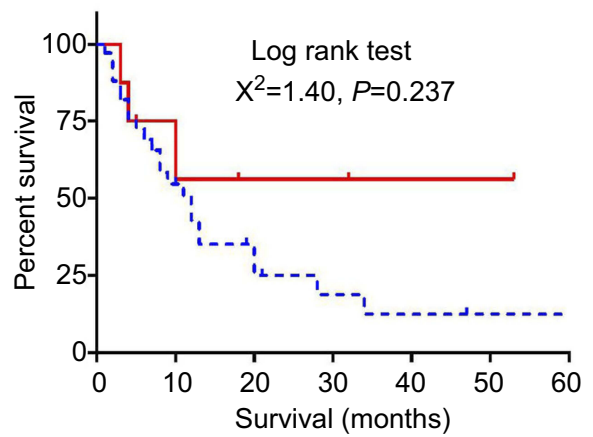

Age $\geq 75$ years

B well differentiated or moderately differentiated

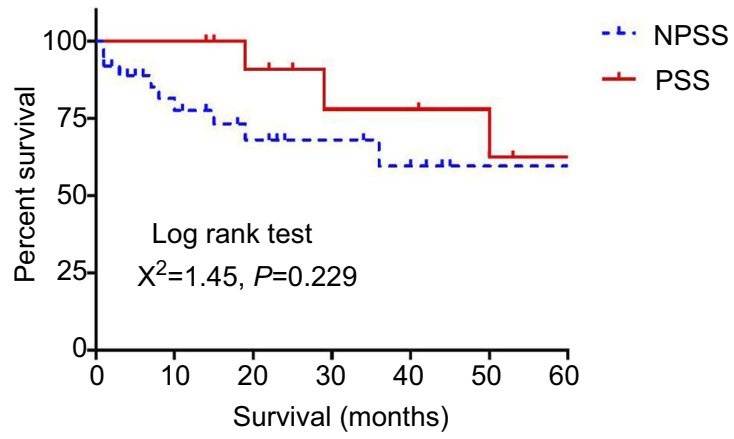

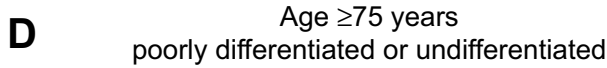

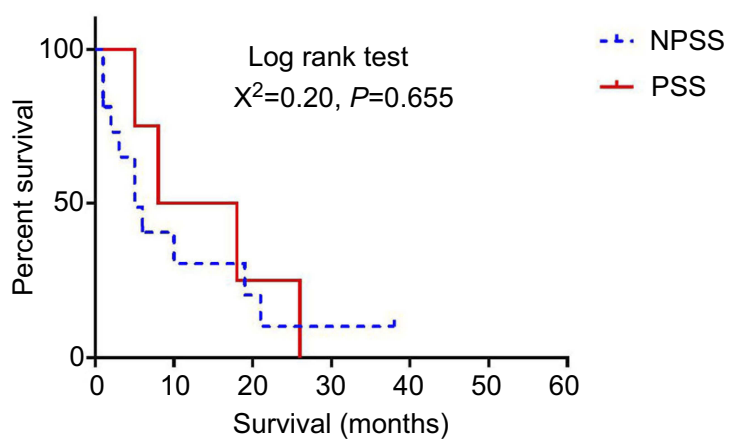

Figure 3 Kaplan-Meier analysis of cancer-specific survival for elderly patients ( $\geq 65$ years) in sub-groups.

Notes: (A) Kaplan-meier analysis for cancer-specific survival in patients with age between 65 and 74 years and tumor of well or moderately differentiation; (B) Kaplanmeier analysis for cancer-specific survival in patients with age $\geq 75$ years and tumor of well or moderately differentiation; (C) Kaplan-meier analysis for cancer-specific survival in patients with age between 65 and 74 years and tumor of poorly differentiation or undifferentiation; (D) Kaplan-meier analysis for cancer-specific survival in patients with age $\geq 75$ years and tumor of poorly differentiation or undifferentiation.

PSS. Patients in the sub-group of age 65-74 years+ well or moderately differentiated achieved a prolonged survival after surgery. However, given the possible existing selection bias, the prolonged survival after surgery may not be entirely attributed to surgery. Careful evaluation should be performed before surgery and various treatment options should be in consideration. In a word, the results of this study have some implications for the treatment of these patients, but prospective randomized controlled studies are still necessary for concluding a decision of surgery.

\section{Conclusion}

Not all elderly patients with distant metastatic pNET could benefit from PSS. Patients aged 65-74 with well or moderately differentiated tumor may benefit from primary lesion surgery, but should be evaluated carefully and in consideration of various treatment options. Patients aged $\geq 75$ years with well or moderately differentiated tumor, and patients aged $\geq 65$ years with poorly differentiated and undifferentiated tumor may not benefit from PSS. Prospective randomized controlled trials are worth performing.

\section{Ethical approval}

This study does not contain any studies with human participants or animals performed by any of the authors. In addition, according to the guidelines of the government of the United States, data released through the SEER database does not require informed patient consent.

\section{Acknowledgment}

We are deeply grateful to Ye-li Huang and Hui-yu Jin from the Nursing Department of The Sixth Medical Center of People's Liberation Army General Hospital for their contributions to the revision of this article. 


\section{Disclosure}

The authors report no conflicts of interest in this work.

\section{References}

1. Dasari A, Shen C, Halperin D, et al. Trends in the incidence, prevalence, and survival outcomes in patients with neuroendocrine tumors in the United States. JAMA Oncol. 2017;3:1335-1342. doi:10.1001/ jamaoncol.2017.0589

2. Zhu LM, Tang L, Qiao XW, et al. Differences and similarities in the clinicopathological features of pancreatic neuroendocrine tumors in china and the United States: a multicenter study. Medicine (Baltimore). 2016;95:e2836. doi:10.1097/MD.0000000000004864

3. Shimata K, Sugawara Y, Hibi T. Liver transplantation for unresectable pancreatic neuroendocrine tumors with liver metastases in an era of transplant oncology. Gland Surgery. 2018;7:42-46. doi:10.21037/ gs.2017.12.11

4. Hallet J, Law CH, Cukier M, Saskin R, Liu N, Singh S. Exploring the rising incidence of neuroendocrine tumors: a population-based analysis of epidemiology, metastatic presentation, and outcomes. Cancer. 2015;121:589-597. doi:10.1002/cncr.29099

5. Halfdanarson TR, Rabe KG, Rubin J, Petersen GM. Pancreatic neuroendocrine tumors (PNETs): incidence, prognosis and recent trend toward improved survival. Ann Oncol. 2008;19:1727-1733. doi:10.1093/annonc/mdn351

6. Bilimoria KY, Talamonti MS, Tomlinson JS, et al. Prognostic score predicting survival after resection of pancreatic neuroendocrine tumors: analysis of 3851 patients. Ann Surg. 2008;247:490-500. doi:10.1097/SLA.0b013e31815b9cae

7. Bertani E, Fazio N, Botteri E, et al. Resection of the primary pancreatic neuroendocrine tumor in patients with unresectable liver metastases: possible indications for a multimodal approach. Surgery. 2014;155:607-614. doi:10.1016/j.surg.2013.12.024

8. Frilling A, Clift AK. Therapeutic strategies for neuroendocrine liver metastases. Cancer. 2015;121:1172-1186. doi:10.1002/cncr.28760
9. Rindi G, D’Adda T, Froio E, Fellegara G, Bordi C. Prognostic factors in gastrointestinal endocrine tumors. Endocr Pathol. 2007;18:145149. doi:10.1007/s12022-007-0020-x

10. Auernhammer CJ, Spitzweg C, Angele MK, et al. Advanced neuroendocrine tumours of the small intestine and pancreas: clinical developments, controversies, and future strategies. Lancet Diabetes Endocrinol. 2018;6:404-415. doi:10.1016/S2213-8587(17)30401-1

11. Frilling A, Modlin IM, Kidd M, et al. Recommendations for management of patients with neuroendocrine liver metastases. Lancet Oncol. 2014;15:e8-e21. doi:10.1016/S1470-2045(13)70362-0

12. Chawla A, Williams RT, Sich N, et al. Pancreaticoduodenectomy and metastasectomy for metastatic pancreatic neuroendocrine tumors. $J$ Surg Oncol. 2018;118:983-990. doi:10.1002/jso.25219

13. Cheng KK, Lim EY, Kanesvaran R. Quality of life of elderly patients with solid tumours undergoing adjuvant cancer therapy: a systematic review. BMJ Open. 2018;8:e018101. doi:10.1136/bmjopen-2017-018101

14. Hidalgo M. Pancreatic cancer. N Engl J Med. 2010;362:1605-1617. doi:10.1056/NEJMra0901557

15. Shamali A, De'Ath HD, Jaber B, et al. Elderly patients have similar short term outcomes and five-year survival compared to younger patients after pancreaticoduodenectomy. Int J Surg. 2017;45:138143. doi:10.1016/j.ijsu.2017.07.106

16. Camp RL, Dolled-Filhart M, Rimm DL. X-tile: a new bio-informatics tool for biomarker assessment and outcome-based cut-point optimization. Clin Cancer Res. 2004;10:7252-7259. doi:10.1158/10780432.CCR-04-0713

17. Falconi M, Eriksson B, Kaltsas G, et al. ENETS consensus guidelines update for the management of patients with functional pancreatic neuroendocrine tumors and non-functional pancreatic neuroendocrine tumors. Neuroendocrinology. 2016;103:153-171. doi:10.1159/000443171

18. Pavel M, O'Toole D, Costa F, et al. ENETS consensus guidelines update for the management of distant metastatic disease of intestinal, pancreatic, bronchial Neuroendocrine Neoplasms (NEN) and NEN of unknown primary site. Neuroendocrinology. 2016;103:172-185. doi: $10.1159 / 000443167$ 


\section{Supplementary materials}

Table SI Multivariate regression analysis of characteristics for cancer-specific survival in patients with age $65-74$ years + well or moderately differentiated

\begin{tabular}{|c|c|c|c|}
\hline \multirow[t]{2}{*}{ Variables } & \multicolumn{2}{|c|}{ Multivariate analysis for CSS } & \multirow[b]{2}{*}{$p$} \\
\hline & HR & $95 \% \mathrm{Cl}$ & \\
\hline \multicolumn{4}{|l|}{ Gender } \\
\hline Male & I (Referent) & & \\
\hline Female & 1.887 & $0.794-4.485$ & 0.151 \\
\hline \multicolumn{4}{|l|}{ Race } \\
\hline White & I (Referent) & & \\
\hline Black & 0.676 & $0.183-2.492$ & 0.556 \\
\hline Other & 0.919 & $0.111-7.615$ & 0.937 \\
\hline \multicolumn{4}{|c|}{ Marital status } \\
\hline Married & I (Referent) & & \\
\hline Unmarried & 1.677 & $0.736-3.823$ & 0.219 \\
\hline \multicolumn{4}{|c|}{ Year of diagnosis } \\
\hline $1973-2009$ & I (Referent) & & \\
\hline $2010-2015$ & 2.286 & $0.944-5.534$ & 0.068 \\
\hline \multicolumn{4}{|l|}{ Tumor site } \\
\hline Head & I (Referent) & & \\
\hline Body/tail & 0.963 & $0.398-2.329$ & 0.933 \\
\hline Overlap & 1.266 & $0.415-3.863$ & 0.679 \\
\hline Other & 2.908 & $0.816-10.367$ & 0.100 \\
\hline \multicolumn{4}{|l|}{ Tumor size } \\
\hline$\leq 4 \mathrm{~cm}$ & I (Referent) & & \\
\hline$>4 \mathrm{~cm}$ & 1.835 & $0.822-4.096$ & 0.138 \\
\hline Unknown & 0.620 & $0.216-1.782$ & 0.375 \\
\hline \multicolumn{4}{|c|}{ Primary site surgery } \\
\hline No & I (Referent) & & \\
\hline Yes & 0.142 & $0.053-0.379$ & 0.000 \\
\hline
\end{tabular}


Table S2 Multivariate regression analysis of characteristics for cancer-specific survival in patients with age $\geq 75$ years + well or moderately differentiated

\begin{tabular}{|c|c|c|c|}
\hline \multirow[t]{2}{*}{ Variables } & \multicolumn{2}{|c|}{ Multivariate analysis for CSS } & \multirow[t]{2}{*}{$p$} \\
\hline & HR & $95 \% \mathrm{Cl}$ & \\
\hline \multicolumn{4}{|l|}{ Gender } \\
\hline Male & I (Referent) & & \\
\hline Female & 1.899 & $0.270-13.335$ & 0.519 \\
\hline \multicolumn{4}{|l|}{ Race } \\
\hline White & I (Referent) & & \\
\hline Black & & & \\
\hline Other & 28.922 & $1.998-418.6$ & 0.014 \\
\hline \multicolumn{4}{|c|}{ Marital status } \\
\hline Married & I (Referent) & & \\
\hline Unmarried & 0.582 & $0.103-3.289$ & 0.582 \\
\hline \multicolumn{4}{|c|}{ Year of diagnosis } \\
\hline $1973-2009$ & I(Referent) & & \\
\hline $2010-2015$ & 0.408 & $0.097-1.719$ & 0.222 \\
\hline \multicolumn{4}{|l|}{ Tumor site } \\
\hline Head & I (Referent) & & \\
\hline Body/tail & 2.483 & $0.447-13.785$ & 0.307 \\
\hline \multicolumn{4}{|l|}{ Overlap } \\
\hline Other & 17.690 & $0.918-340.8$ & 0.057 \\
\hline \multicolumn{4}{|l|}{ Tumor size } \\
\hline$\leq 4 \mathrm{~cm}$ & I (Referent) & & \\
\hline$>4 \mathrm{~cm}$ & 0.166 & $0.036-0.764$ & 0.037 \\
\hline Unknown & 1.213 & $0.179-8.215$ & 0.843 \\
\hline \multicolumn{4}{|c|}{ Primary site surgery } \\
\hline No & I (Referent) & & \\
\hline Yes & 1.150 & $0.130-10.165$ & 0.900 \\
\hline
\end{tabular}


Table S3 Multivariate regression analysis of characteristics for cancer-specific survival in patients with age $65-74$ years + poorly differentiated or undifferentiated

\begin{tabular}{|c|c|c|c|}
\hline \multirow[t]{2}{*}{ Variables } & \multicolumn{2}{|c|}{ Multivariate analysis for CSS } & \multirow[t]{2}{*}{$p$} \\
\hline & HR & $95 \% \mathrm{Cl}$ & \\
\hline \multicolumn{4}{|l|}{ Gender } \\
\hline Male & I (Referent) & & \\
\hline Female & 1.143 & $0.349-3.746$ & 0.825 \\
\hline \multicolumn{4}{|l|}{ Race } \\
\hline White & I (Referent) & & \\
\hline Black & 3.047 & $0.748-12.406$ & 0.120 \\
\hline Other & 0.656 & $0.066-6.505$ & 0.719 \\
\hline \multicolumn{4}{|c|}{ Marital status } \\
\hline Married & I (Referent) & & \\
\hline Unmarried & 1.444 & $0.520-4.014$ & 0.481 \\
\hline \multicolumn{4}{|c|}{ Year of diagnosis } \\
\hline $1973-2009$ & I (Referent) & & \\
\hline $2010-2015$ & 0.802 & $0.304-2.118$ & 0.656 \\
\hline \multicolumn{4}{|l|}{ Tumor site } \\
\hline Head & I (Referent) & & \\
\hline Body/tail & 0.914 & $0.330-2.531$ & 0.863 \\
\hline Overlap & 0.719 & $0.168-3.090$ & 0.658 \\
\hline Other & 0.760 & $0.068-8.540$ & 0.824 \\
\hline \multicolumn{4}{|l|}{ Tumor size } \\
\hline$\leq 4 \mathrm{~cm}$ & I (Referent) & & \\
\hline$>4 \mathrm{~cm}$ & $0.84 I$ & $0.302-2.341$ & 0.740 \\
\hline Unknown & 0.986 & $0.285-3.413$ & 0.983 \\
\hline \multicolumn{4}{|c|}{ Primary site surgery } \\
\hline No & I (Referent) & & \\
\hline Yes & 0.621 & $0.174-2.218$ & 0.463 \\
\hline
\end{tabular}


Table S4 Multivariate regression analysis of characteristics for cancer-specific survival in patients with age $\geq 75$ years + poorly differentiated or undifferentiated

\begin{tabular}{|c|c|c|c|}
\hline \multirow[t]{2}{*}{ Variables } & \multicolumn{2}{|c|}{ Multivariate analysis for CSS } & \multirow[t]{2}{*}{$p$} \\
\hline & HR & $95 \% \mathrm{Cl}$ & \\
\hline \multicolumn{4}{|l|}{ Gender } \\
\hline Male & I (Referent) & & \\
\hline Female & 0.640 & $0.14 \mid-2.898$ & 0.563 \\
\hline \multicolumn{4}{|l|}{ Race } \\
\hline White & I (Referent) & & \\
\hline Black & & & \\
\hline Other & 8.373 & $1.036-67.700$ & 0.046 \\
\hline \multicolumn{4}{|l|}{ Marital status } \\
\hline Married & I (Referent) & & \\
\hline Unmarried & 1.562 & $0.316-7.708$ & 0.584 \\
\hline \multicolumn{4}{|c|}{ Year of diagnosis } \\
\hline $1973-2009$ & I (Referent) & & \\
\hline $2010-2015$ & 0.380 & $0.064-2.266$ & 0.288 \\
\hline \multicolumn{4}{|l|}{ Tumor site } \\
\hline Head & I (Referent) & & \\
\hline Body/tail & 2.483 & $0.447-13.785$ & 0.307 \\
\hline \multicolumn{4}{|l|}{ Overlap } \\
\hline Other & 17.690 & $0.918-340.8$ & 0.057 \\
\hline \multicolumn{4}{|l|}{ Tumor size } \\
\hline$\leq 4 \mathrm{~cm}$ & I (Referent) & & \\
\hline$>4 \mathrm{~cm}$ & 0.458 & $0.119-1.766$ & 0.257 \\
\hline Unknown & 5.879 & $0.296-116.8$ & 0.245 \\
\hline \multicolumn{4}{|c|}{ Primary site surgery } \\
\hline No & I (Referent) & & \\
\hline Yes & 0.469 & $0.091-2.407$ & 0.364 \\
\hline
\end{tabular}

\section{Publish your work in this journal}

Clinical Interventions in Aging is an international, peer-reviewed journal focusing on evidence-based reports on the value or lack thereof of treatments intended to prevent or delay the onset of maladaptive correlates of aging in human beings. This journal is indexed on PubMed Central, MedLine, CAS, Scopus and the Elsevier
Bibliographic databases. The manuscript management system is completely online and includes a very quick and fair peer-review system, which is all easy to use. Visit http://www.dovepress.com testimonials.php to read real quotes from published authors. 